\title{
Pintura, fotografia e a crítica de arte na pós-modernidade
}

\author{
Marcos Fabris*
}

Resumo: Este artigo pretende apresentar e discutir algumas das características primordiais das imagens produzidas no período convencionalmente designado por "pós-modernismo", almejando estabelecer relações entre os imperativos materiais para a sua produção, o chão histórico sob o qual se assenta e a avaliação feita por uma parcela influente da crítica a este respeito.

Palavras-chave: Pintura. Fotografia. Crítica de arte. Pós-modernismo.

\section{Introdução}

Como compreender o mundo contemporâneo sem explicar as relações existentes entre capital financeiro, sociedade de consumo, cultura de massas, mídia e pósmodernismo? Como os produtores de imagem, mais precisamente os fotógrafos, se inserem no processo de produção imagético pós-moderno, no qual a cultura do dinheiro parece estabelecer diretrizes bastante precisas para a produção artística? E o que seria, afinal, uma "imagem fotográfica pós-moderna"? Quais são os elementos que a caracterizam, por que se apresentam da forma como o fazem e quais os conteúdos sócio-históricos sedimentados neste tipo de produção?

A importância e complexidade destas questões não permitem que nos esquivemos da discussão proposta ou que ofereçamos respostas simplistas às intrincadas e nem sempre aparentes relações entre a hegemonia global do capital, a mercantilização da sociedade e da cultura e suas consequentes manifestações nas produções artísticas - fotografia naturalmente inclusa. Desta maneira, a tentativa de esclarecer tais questões, buscando decifrar alguns dos elementos constitutivos da imagem fotográfica contemporânea (ou pós-moderna), é de fundamental importância não somente para melhor compreendermos a atual produção imagética e suas relações com outras áreas da experiência humana, como também para melhor estabelecer as devidas conexões entre as diversas áreas da experiência social.

As questões acima mencionadas poderiam ser observadas de inúmeras perspectivas. No entanto, acredito que vertentes críticas que pretendem estabelecer relações entre os processos estéticos e os conteúdos sócio-históricos sedimentados na obra deveriam ser utilizadas na análise de nosso objeto. Posto de outra forma, os procedimentos formais utilizados pelos produtores de imagem não têm autonomia

Doutor em Letras pela FFLCH - USP, pós-doutorado em Columbia University (Nova York), pósdoutorado no Museu de Arte Contemporânea da Universidade de São Paulo - MAC USP. 
própria: eles não estão desvinculados dos contextos sócio-históricos que os produziram, não são meros joguetes formais. Assim, gostaria de refletir sobre tais questões norteando-as por balizas críticas caras à crítica materialista, uma das mais importantes tendências críticas que analisam a forma artística como sedimentação do conteúdo sócio-histórico na produção artística.

\section{O esfacelamento das fronteiras entre a alta cultura e a cultura de massas}

Toda a arte modernista da primeira metade do século XX vive e se alimenta da dicotomia que nasce do conflito entre a vocação "realista" da arte, ou seja, a de estabelecer relações com a sociedade de seu tempo através da mimese, e a concepção de que a "cópia" de uma vida que se tornou complexa demais já não é suficiente para revelar a "verdade" de seu momento histórico. O alto grau de fragmentação da vida social (explicitado pelo início das batalhas nas ruas de Paris em 1848 e posteriormente com as batalhas urbanas da Comuna em 1871), consequência da dissolução do projeto burguês de igualdade expresso pela Revolução Francesa de 1789, tornou a realidade cada vez menos passível de compreensão em seu "todo", já que a partir deste momento não há mais a percepção de uma realidade única, coletiva (MARX, 1994). Assim, a cópia "fiel" de um modelo humano na pintura, por exemplo, não mais expressa de modo claro o desespero e a angústia do homem moderno - para ser "realista" é preciso distorcer a realidade e o corpo humano para expressar esta "realidade" mais claramente (pensemos na obra de Picasso ou no homúnculo de Munch em $O$ Grito). Por outro lado, o enredo de ação da literatura e do teatro comerciais, baseado numa visão "simplista" da vida cotidiana, também é uma "mentira": coloca no centro de nossa atenção personagens que, ao contrário do que acontece na vida "real", podem "agir", mudar suas vidas, resolver seus conflitos. Agora, portanto, as formas artísticas nas suas relações com a realidade "visível" devem se dissolver para que a arte possa falar sobre aquilo que está debaixo das aparências. É este o papel da arte de "vanguarda" segundo Theodor Adorno. Contrapondo-se a essa arte de vocação desestabilizadora e revolucionária, estaria a chamada "cultura de massas", depósito de interesses puramente comerciais, inimiga mortal da reflexão crítica. Ao contrário da alta cultura, que tenta manter vivos os ideais mais progressistas da humanidade e denunciar a falsidade da indústria cultural, a linearidade da arte da cultura de massa tentaria facilitar o fluxo e o consumo fácil da arte como mercadoria, mantendo, assim, o status quo.

As distinções culturais acima descritas pareciam muito pertinentes no período modernista. Entretanto, com o avanço do capitalismo globalizado e a colonização da vida por um processo sem precedentes de mercantilização, as fronteiras entre a "arte de vanguarda" e a "cultura de massas" se dissolvem: as áreas da experiência humana, inclusive as produções artísticas, foram colonizadas pelo mercado e estão a serviço da lógica da mercadoria (JAMESON, 1991). Assim, as formas da arte modernista teriam sido, elas também, absorvidas pela cultura de massa na pós-modernidade. Desta maneira, o período denominado pós-moderno, com início no final dos anos 50 ou princípios dos 60 do século $\mathrm{XX}$, é marcado pelo esfacelamento gradual das antigas fronteiras entre as chamadas alta cultura e cultura de massas (ou cultura comercial). 
Esta nova "geografia", (re)definida pela quebra de fronteiras entre estes dois "tipos" de arte, suscita toda sorte de postura ante a produção artística pós-moderna, da apologia do "novo" à estigmatização do material "decaído", produzido sem a "nobreza" de valores da alta (e saudosa, como veremos a seguir) arte modernista. O crítico norte-americano Fredric Jameson alerta que nenhuma destas posturas são de fato esclarecedoras, uma vez que tanto a apologia quanto a estigmatização da atual produção artística são meras tomadas de posição sobre a natureza do capital: os apologistas, por um lado, celebram a vitória do fragmento na pós-modernidade, pois, segundo eles, as narrativas mestras do passado (ou seja, as grandes maneiras de interpretar a vida do ponto de vista da totalidade como o marxismo, a luta de classe ou a própria democracia) são totalitárias. Elas analisam o mundo segundo uma perspectiva logocêntrica e do ponto de vista do discurso hegemônico imperialista, criada nos centros destes grandes impérios. Negando tais narrativas, festejam as formas culturais híbridas (a mistura de etnias, grupos, nacionalidades), a dissolução da posição binária entre centro e periferia e o fluxo livre de cultura.

Em teoria, festejar esta nova humanidade, pluralismo e diversidade não é má ideia: neste "novo" espaço, uma imensa gama de grupos, raças e etnias, que antes estavam restritas a seus pequenos universos, tem a chance de se manifestar. Estas minorias marginalizadas podem agora adquirir visibilidade e "aprendemos" então a respeitar as diferenças. Entretanto, o engodo parece estar precisamente no fato de que o fluxo livre de cultura no mundo pós-moderno está em descompasso com o fluxo do capital, que somente caminha em mão única (CEVASCO, 2001). Como decorrência, são os centros hegemônicos capitalistas quem determinam quais e como se darão as trocas culturais e artísticas. Desta maneira, os apologistas, no intuito de defender a quebra do paradigma centro-periferia, apenas o ratificam e o revigoram ao camuflar suas questões sócio-históricas centrais. Por outro lado, aqueles que estigmatizam a produção pós-moderna negam o possível valor da cultura de massa e afastam-se dos debates e questões contemporâneas, como a (aparente) impossibilidade de modos coletivos de interpretação. Assumindo muitas vezes uma posição elitista e saudosista, cultuam a ideia de que é a grande obra modernista quem resguarda os verdadeiros valores da cultura negativa ${ }^{1}$, não se dando conta de que ela também se tornou mercadoria - como lembra o crítico inglês Terry Eagleton, grandes obras de mestres modernistas pertencem e estão expostas em gigantescas instituições financeiras (EAGLETON, 1990) e se negando a compreender a arte e sociedade contemporâneas. É desta maneira que nem a apologia nem a estigmatização do material pós-moderno auxilia na sua compreensão.

A proposta de Jameson para o melhor entendimento da produção artística pósmoderna e de suas relações com seus contextos sócio-históricos é de, sem festejar ou estigmatizar, desenvolver um instrumento analítico que denominou "mapeamento cognitivo" (JAMESON, 1991): uma série de práticas interpretativas que visam estabelecer conexões entre as relações locais da experiência subjetiva e as forças abstratas e impessoais do sistema global (HARDT e WEEKS, 2000). Em outras

${ }^{1} \mathrm{O}$ termo é aqui utilizado segundo a definição de cultura negativa de $\mathrm{H}$. Marcuse: a negação do status quo e das condições existentes. In Marcuse, H. Cultura e sociedade. São Paulo, Paz e Terra, 1997. 
palavras, este mapeamento é um ato interpretativo que procura relacionar os fragmentos (que no pós-modernismo parecem adquirir "vida própria"), tentando compreendê-los dentro de uma perspectiva de relações muitas vezes obscurecidas com o todo ao qual estão relacionados. Assim, o mapeamento cognitivo proposto por Fredric Jameson pode ser, conforme a definição de ideologia do crítico francês Louis Althusser, uma tentativa de compreensão da representação imaginária de nossas relações com nossas reais condições de existência. Assim, Jameson, munido deste instrumento de análise, propõe que sem celebração ou condenação do material artístico pós-moderno, um debate se inicie em torno da seguinte questão: "Qual o (possível) poder que as obras pós-modernistas têm de revelar o conteúdo de verdade sócio-histórico de seu tempo?" (JAMESON 1991). A tentativa de responder tal questão nestes termos propõe que o pós-modernismo seja abordado de forma histórica e não meramente estilística. Este seria, segundo Jameson, um possível caminho para desmascarar as atuais estruturas de dominação econômicas e culturais imperialistas, encobertas inclusive pelo mito da globalização pós-moderna, explicitando e elucidando questões referentes ao aparente fim da possibilidade de movimentos coletivos de natureza político-libertária (principalmente a partir do final dos anos 50 , início do pósmodernismo) e de narrativas mestras que auxiliem a interpretação e compreensão das relações sociais do ponto de vista da totalidade.

\section{O "estilo" pós-moderno}

A pergunta acima proposta por Jameson gira em torno de uma série de questões a ela relacionadas, uma delas ligada à questão do estilo no pós-modernismo. 0 conceito de estilo como quebra de paradigma, característico no período modernista e expresso pelos movimentos de vanguarda, desaparece por completo na pósmodernidade. As conquistas formais de artistas modernos como Picasso, Joyce ou Schönberg, ligadas à utilização de recursos anti-ilusionistas, ou seja, recursos que desmascaram a ilusão de arte como cópia "fiel" da realidade, foram completamente incorporadas e institucionalizadas no pós-modernismo. Esta institucionalização de procedimentos formais na produção cultural pós-moderna, que outrora foram avantgarde e punham em cheque a mera fruição estética e os diversos processos de identificação sem a devida reflexão e distanciamento críticos, serve hoje a interesses específicos para estimular e facilitar a produção, o fluxo e o consumo de mercadorias num mundo globalmente dominado pela economia de mercado. Tomemos por exemplo as conquistas formais cinematográficas de Sergei Eisenstein. Se no alto modernismo o cineasta russo utilizava-se de recursos de montagem baseados no choque abrupto de imagens, claramente de cunho revolucionário, em filmes como $O$ Encouraçado Potemkin, Greve ou Outubro, buscando uma forma artística que mimetizasse o choque revolucionário tanto no conteúdo das imagens como na própria forma utilizada, hoje estes mesmos recursos foram apropriados por outros veículos para falarem de outros conteúdos, por exemplo, os vídeo-clips apresentados pela gigantesca rede de televisão americana MTV - Music Television e consumidos por um sem-número de telespectadores. Também na fotografia não nos faltam exemplos. Todas as conquistas 
formais de fotógrafos como Atget (e seu surrealismo avant la lettre ${ }^{2}$ ), Rodchenko (e a alteração do ponto de vista tradicional) ou Kertész (e suas distorções da forma humana) estão hoje a serviço da fotografia publicitária ou de moda. Em todos estes casos, muito do recurso criativo modernista tornou-se mais uma saída para facilitar e ratificar tanto o fluxo de mercadorias como a própria lógica da economia de mercado (lembremo-nos de que o objetivo maior de um vídeo-clip é vender seu produto musical bem como tudo que a ele se relaciona, do cd à imagem fabricada pelo/para o artista; este também é o principal propósito da fotografia publicitária ou aquela ligada à moda).

Portanto, o que era estilo modernista transforma-se em mero código pósmoderno absorvido e incorporado à lógica da economia de mercado. Desta maneira, por não se distinguirem mais os procedimentos estilísticos formais com objetivos semelhantes àqueles utilizados no modernismo, não seria adequado falar em um "estilo pós-moderno", mas sim em uma mudança contínua entre os mais diversos estilos anteriores, desligados de seus referenciais sócio-históricos. O pós-modernismo seria, por conseguinte, não um "estilo" mas um "dominante cultural" (JAMESON, 1991).

Considerando-se a questão estilística na pós-modernidade, a pergunta inicialmente posta, ou seja, "qual o (possível) poder que as obras pós-modernistas têm de revelar o conteúdo de verdade sócio-histórico de seu tempo?" (JAMESON, 1991) ramifica-se e nos chama a atenção para um outro aspecto desta mesma questão, a saber, a relação entre a forma pós-modernista e sua possível capacidade de expressar conteúdos de "verdade". Posto de outra maneira, poderíamos nos perguntar: pode-se, de fato, através da análise dos códigos pós-modernos, meros dominantes culturais que obviamente servem a interesses mercadológicos, e portanto falsificados, identificar momentos de "verdade" dentro dos mais evidentes momentos de "mentira" expressos nas obras pós-modernistas?

\section{A imagem pós-moderna}

Retornando ao conceito de mapeamento cognitivo proposto por Jameson, a obra de arte no capitalismo teria, em maior ou menor grau, e apesar de colonizada por este sistema, um poder intrínseco de revelar algo sobre seu tempo ${ }^{3}$ : por um lado ela se oferece como mercadoria num processo de reificação; entretanto também sinaliza determinados vetores utópicos. Se no modernismo estes vetores utópicos eram mais perceptíveis (pensemos novamente na obra de Picasso), no pós-modernismo eles encontram-se mais camuflados do que nunca. O caráter a-histórico presente na obra de arte pós-moderna, ou seja, a história escondida atrás da aparente falta de história expressa na obra é, na verdade, um índice da história de seu tempo: o material com

${ }^{2}$ Embora existam controvérsias no que diz respeito ao surrealismo avant la lettre de Atget, alguns autores como Benjamin e Maillet afirmam que o fotógrafo prenuncia a chamada fotografia surrealista, na medida em que desinfeta a atmosfera sufocante difundida pela fotografia convencional, especializada em retratos, iniciando um processo que propicia a libertação do objeto de sua aura.

3 Esta ideia relaciona-se ao conceito hegeliano de que o procedimento formal é o próprio conteúdo sócio histórico decantado. 
que o artista trabalha é sempre e necessariamente as relações sócio-históricas contemporâneas à sua produção. Como observou Jameson, estas relações oferecem uma determinada "resistência" que se impõe na análise independentemente das diversas maneiras de tentar camuflá-las (JAMESON, 1995). Desta forma, os vetores utópicos presentes na obra de arte têm poder de revelar as condições imaginárias das relações expressas com as reais condições de existência dos indivíduos em sua época de produção, ou seja, o poder de expressar "o que não é", "o que falta", "o que poderia ser", através de uma lacuna no centro da representação. Até mesmo num nível mais primário, a própria insistência, por exemplo, do cinema comercial em construir narrativas que encontrem "solução" imaginária no final, já denuncia um mundo no qual as soluções já não parecem possíveis. Jameson esclarece:

Deste modo, já começamos a apresentar uma justificativa para abordar o cinema comercial como um meio em que seria possível detectar uma eventual mudança no caráter de classe da realidade social, uma vez que a realidade social e os estereótipos de nossa experiência da realidade social cotidiana constituem a matéria-prima com que os filmes comerciais e a televisão são inevitavelmente forçados a trabalhar. É essa a minha resposta, por antecipação, aos críticos que, a priori, fazem objeção à presença de qualquer conteúdo genuinamente político, pois que os vultosos custos dos filmes comerciais, que inevitavelmente submetem sua produção ao controle das corporações multinacionais, tornam improvável a presença de qualquer conteúdo político genuíno, ao mesmo tempo que asseguram a vocação dos filmes comerciais para veículos de manipulação ideológica. Não há dúvida de que é isso o que ocorre, se nos ativermos apenas à intenção do cineasta, que tem que se limitar, consciente ou inconscientemente, às circunstâncias objetivas. Mas esse argumento nega a identificação com o conteúdo político da vida cotidiana, com a lógica política que já é inerente à matéria-prima com que o cineasta precisa trabalhar: uma lógica política como essa não irá, portanto, manifestar-se como uma mensagem política explícita, tampouco transformará o filme em uma declaração política livre de ambiguidades. Irá, contudo, contribuir para o surgimento de profundas contradições formais, às quais o público não pode deixar de notar, tenha ou não os instrumentos conceituais para compreender o que tais contradições significam. (JAMESON, 1995, p. 39).

Jameson identifica uma ruptura entre o modernismo e o pós-modernismo no que diz respeito à figuração dos vetores utópicos acima mencionados. Até o modernismo, parecia ser possível produzir figurações nas quais a arte, oferecendo-se como mercadoria, também se mantinha imersa na história, ou seja, o mundo do trabalho não era (completamente) eliminado e uma ideia de vínculo com a totalidade ainda era possível. Já no pós-modernismo, os contextos sócio-históricos são eliminados da figuração através da fragmentação da forma para que o vetor utópico seja mantido. Com a eliminação dos contextos sócio-históricos, tem-se a consequente eliminação do conceito de totalidade, ratificando-se ainda mais o caráter reificado da obra. Agora os objetos figurados passam a ser meros simulacros, ou seja, representações desprovidas de contextos humanos e esvaziadas de conteúdos. Neste tipo de figuração o objeto é representado como oco, uma vez que seu conteúdo tornase irrelevante (desde que o fluxo da arte como mercadoria esteja de alguma maneira assegurado). Esta forma de figuração seria a tônica do pós-modernismo: a produção de "imagens-cópias" de originais que jamais existiram. Vejamos como esta relação entre "fragmento" e "compensação utópica" se equaciona e qual seu potencial cognitivo em dois momentos distintos sugeridos por Jameson: a produção artística de Vincent Van Gogh e a de Andy Warhol. 
Em Um par de sapatos, de1887, Van Gogh representa as botas de um camponês de modo a transformar um universo árduo em algo exuberante (STEIN, 1986). O mesmo é válido para outras obras como Semeador com Sol se Pondo, de 1888 ou $A$ Arlesiana, de 1888: o campo e o trabalhador explodem em uma superfície de cores e os estereótipos dos habitantes do vilarejo, criaturas exauridas pelo trabalho e caricaturas de uma tipologia humana quase grotesca, são retratados com exuberante profusão de cores. Toda esta explosão cromática tenta, de certo modo, compensar as reais condições de existência do objeto retratado. Entretanto, as botas têm história: estão inscritas numa sucessão temporal, têm ontem, hoje e amanhã e estão imersas num contexto humano que Ihes dão seu caráter.

Já nos sapatos "pós-modernos" de Warhol, intitulados Diamond Dust Shoes (1980), percebe-se uma abordagem essencialmente distinta daquela utilizada por Van Gogh: o trabalho de Warhol gira em torno da mercantilização. Posto de outra maneira, a relação entre arte e mercadoria, até então mascarada no campo das artes, é explicitada por Warhol, inclusive quando retrata a própria mercadoria como assunto de suas obras: sopas Campbell, garrafas de Coca-Cola e embalagens de sabão em pó (sem falar nos retratos de figuras famosas como Marilyn Monroe ou Mao Tse-Tung, estes também transformados em imagens-simulacro). Assim, a "narrativa" desaparece bem como os contextos humanos.

Se no movimento modernista esta relação entre arte e mercadoria explicitada por Warhol é posta como uma angústia das questões estéticas, no pós-modernismo a arte se põe explicitamente como mercadoria e a angústia moderna transforma-se em pura euforia estética pós-moderna. Assim, o querer ir além da forma, como na obra de Van Gogh, não é mais uma questão, uma vez que no pós-modernismo existe total dissociação entre forma e conteúdo: ao contrário da obra de Van Gogh, o mundo do trabalho e a própria história só estão presentes na obra de Warhol - e da maioria dos artistas pós-modernos - através de suas ausências. Segundo Lyotard, as intensidades estéticas vagam sobre o conteúdo: não há mais relação orgânica entre a forma utilizada e o conteúdo expresso (novamente a presença do simulacro). Desta maneira, agora é a mercadoria quem passa a ser o astro da obra.

Na maior parte das imagens produzidas sob este regime, percebe-se uma nova forma de achatamento, um novo tipo de superficialidade - em sua forma mais literal. Este novo tipo de achatamento é outro procedimento formal pós-moderno por excelência (JAMESON, 1991). Assim, se os sapatos de Van Gogh estão imersos na História, os sapatos de Warhol estão imersos em "nada", atuando como personagens principais nesta nova falta de profundidade de campo.

Novamente pensando nas questões referentes ao pós-modernismo não somente em termos estilísticos mas também em termos históricos, percebe-se que esta nova ausência de profundidade é oriunda da crise do conceito de espaço, ligada por sua vez à crise do capital contemporâneo. A história do capital já viveu sua fase nacional de desenvolvimento, com expansão dos mercados internos, sua fase internacional com a expansão imperialista para conquista de novos mercados e agora esgota suas últimas possibilidades em sua fase multinacional ou global, com a economia mundial de mercado dominada econômica e culturalmente pelos Estados Unidos da América em 
cada canto recôndito do planeta, que pode agora ser alcançado num piscar de olhos através do emprego da tecnologia cibernética. Portanto, neste atual momento da história, os espaços já não podem ser ampliados uma vez que não existem mais espaços disponíveis para colonização/dominação: como resolver as atuais crises econômicas do sistema global e para onde dirigir energias se todo o planeta está integrado no fluxo de capital internacional? Assim, esta crise do conceito de espaço é refletida nesta nova forma de achatamento: o espaço "encolhe", "desaparece" e a profundidade e a perspectiva são substituídas pela superficialidade 4 .

Esta maneira "a-histórica" de figuração presente na obra de arte pós-moderna merece consideração e deve, como todas as outras formas de figuração, ser historicizada, pois tais procedimentos não são meros recursos autônomos que se descolam da história como se fossem apenas mais uma solução artística de ordem puramente estilística. Ao contrário, eles estão inseridos e fazem parte de complexas redes de relações sócio-históricas e devem, portanto, ser considerados sob esta ótica (HARDT e WEEKS, 2000). Assim, esta figuração "a-histórica", ou seja, a "ausência" da história na obra de arte pós-moderna, aquele "nada" no qual a obra parece estar imersa, revela a presença da história justamente através de sua aparente ausência. Aqui o conceito de mapeamento cognitivo proposto por Jameson revela-se uma ferramenta útil para melhor compreendermos a questão da figuração "a-histórica". O entendimento do referente histórico é condição fundamental para o entendimento do momento presente. Na medida em que, como acontece na obra de arte pós-moderna, este referente histórico desaparece e o sentido de historicidade é dissipado, quando a ideia de história como projeto coletivo é esvaziada ou "inviabilizada", quando o fim de movimentos coletivos de natureza político-libertárias e de narrativas mestras que auxiliam a interpretar a vida do ponto de vista da coletividade e da totalidade são "decretados", nasce a ideia do "fim da história"5.

No entanto, como num processo freudiano de repressão, o reprimido reaparece de outras formas, por outros meios (FREUD, 1986). Assim, a história, de modo inexorável, "entra pela porta dos fundos", retornando na imagem de diferentes maneiras através de "lacunas" na figuração: o "nada" na qual parece estar imersa, o simulacro de originais inexistentes, a dissociação entre forma e conteúdo, a euforia estética pós-moderna. A história é, portanto, reinventada em um nível puramente estetizado no pós-modernismo. Trata-se aqui de um processo de reinvenção da história sob a ótica da imagem reificada, ou seja, sob a ótica de uma nostalgia que transforma a História em "pop-history". Entretanto, todos estes indícios, os dominantes culturais pós-modernos, que em teoria nos deveriam levar a crer no fim da história são efetivamente parte da própria história.

\footnotetext{
${ }^{4}$ Não nos esqueçamos que a perspectiva artificialis renascentista prenunciava o novo horizonte antropocêntrico e os espaços a serem conquistados e colonizados pela ação de um novo e poderoso grupo que surgia e se consolidava social e economicamente: a burguesia. É desta maneira que percebemos como a Mona Lisa renascentista de da Vinci, também imersa na História assim como os sapatos de Van Gogh, tornar-se-ia uma outra Mona Lisa, aquela pósmoderna de um Vik Muniz, a qual não tem qualquer profundidade: é uma figura "achatada", representada num "não-espaço" "a-histórico" que revela sua própria crise.

${ }^{5}$ Como proposto por Francis Fukuyama.
} 
Esta crise do conceito de história incentiva a perda do controle sobre a organização da experiência humana como um todo, dificultando sua melhor compreensão. A produção artística pós-moderna reflete esta crise e a figura, na medida em que se utiliza da representação do fragmento e não do todo para "expressar" seus "conteúdos". Esta é outra característica da produção pós-moderna: a ênfase na figuração dos fragmentos. Estes, por sua vez, com suas relações obscurecidas com o todo ao qual se relacionam, parecem adquirir completa autonomia, tornando-se "independentes" uns dos outros - e portanto completamente aleatórios. Posto de outra maneira, ao perder-se a ideia de totalidade figura-se apenas o fragmento, decorrendo daí a impressão de que todas estas frações são instâncias completamente autônomas, homogêneas e não mais passíveis de interpretação histórica. Nenhum destes detalhes parecem passíveis de serem fixados historicamente; eles mudam de significado a cada instante, atribuindo à obra de arte pós-moderna um caráter altamente fragmentário e esquizofrênico.

Tomemos novamente o vídeo-clip, exemplo potencialmente esclarecedor para a melhor compreensão do caráter esquizofrênico e fragmentário da obra pós-moderna e suas relações com o cinema modernista. Um filme modernista pretende estabelecer relações concretas entre o fragmento e o todo ao qual se relaciona: suas imagens e sequência não são aleatórias e um projeto no qual o fragmento tem uma clara função apresentado. Pensemos em Un Chien Andalou (1928), um filme com duração de dezessete minutos dirigido por Luis Buñuel e Salvador Dalí. Já na cena de abertura, um olho humano que é cortado ao meio por uma navalha, Buñuel e Dalí sugerem uma outra maneira de "ver": a fragmentação da narrativa proposta no filme ataca a reificação da sociedade burguesa através de imagens que propõe um caráter "irracional" (baseado na fragmentação das imagens do sonho e do inconsciente) que vai contra uma forma de organização linear, baseada em relações de causa e efeito, ou seja, "lógica", "administrável". Un Chien Andalou propõe com sua escolha e sequência de imagens um ataque direto a uma narrativa mestra (o sistema capitalista e sua organização quantificadora) em nome de outra (a visão utópica de uma forma oposta àquela). A narrativa do filme é, sim, fragmentada porém esta fragmentação (neste caso surrealista) tem como paradigma o sonho, a fantasia, o desejo não reificado e os impulsos primitivos anteriores ao capital. Um vídeo-clip feito no final do século XX ou início do século XXI é, ao contrário, frequentemente composto por uma série de imagens completamente aleatórias e "equivalentes", uma vez que não parecem ter por objetivo ilustrar a letra da música apresentada ou tecer um projeto narrativo. As imagens, normalmente belas, atraentes e tecnologicamente bem construídas e acabadas, apelam aos sentidos da visão apenas como meros adereços. Não têm ou pedem qualquer interpretação, já que seu objetivo é apenas o de falar a linguagem da mercadoria.

Esta fragmentação esquizofrênica, quando torna-se norma cultural, obscurece todas as possíveis formas de efeito negativo (no sentido de negar e possivelmente reverter este processo de fragmentação) e disponibiliza-se somente para usos estritamente decorativos. Entretanto, dialeticamente está precisamente aí apontado o papel cognitivo da crítica à imagem pós-moderna: em sua função crítica de revelação da negação do estado das coisas e do simulacro no qual a imagem se apresenta. 
A mesma questão exemplificada pelo vídeo-clip poderia ser também discutida com exemplos da arte fotográfica e sua produção pós-moderna: o detalhe fotografado estabelece de fato relações concretas com alguma ideia de totalidade? Nas imagens do fotógrafo brasileiro Pedro Martinelli sobre o Amazonas percebe-se a tentativa do fotógrafo de estabelecer conexões entre o fragmento e o todo no qual ele se insere. Em PanaPana, Rio Içana - setembro 1997 o detalhe fotografado, as mãos adornadas e calejadas de um jovem trabalhador contextualiza o fragmento, relacionando-o com outros fragmentos apresentados na mesma obra (como aquele apresentado na página ao lado: Lagoa do Capeta - janeiro 1996) para assim tecer uma narrativa sobre o mundo do trabalho no qual aquele homem está inserido. Em seu trabalho existe um "ontem", "hoje" e "amanhã", ou seja, uma linha narrativa ao longo da qual a História se desenvolve. Já no trabalho de Araquém Alcântara, fotógrafo que registrou a Amazônia bem como outros lugares "exóticos" do país, percebe-se como o fragmento se descola de seu todo, adquirindo "vida própria". Em Queda d'água, uma cachoeira é completamente distorcida de modo a transformar-se em um detalhe multicolorido e texturizado que não se refere a nada que não seja ele mesmo. Nas imagens de Alcântara a natureza apresenta-se reificada da mesma forma como o homem que com ela "interage": Casa de pedra ou Folião de Rei mostram fragmentos deste homem exótico, colorido, mercantilizado. Em outras palavras, suas imagens limitam-se a oferecer apenas uma experiência estética, completamente descontextualizada de seus referentes sócio-históricos. Assim como um vídeo-clip pós-moderno, a obra de Alcântara não pretende estabelecer qualquer projeto narrativo: são imagens "autosuficientes" que ratificam clichês e estereótipos exóticos tanto da população local como da fauna e flora da região, utilizando-se de várias das características da imagem pósmoderna aqui mencionadas, tais como o simulacro, o achatamento do sujeito e o auxílio de recursos tecnológicos de ponta para a produção imagética, unicamente com o intuito de facilitar o fluxo da arte e da imagem como mercadoria. Ao contrário de Martinelli, Alcântara procura utilizar-se de pontos de vistas tradicionais de observação na produção de suas imagens, ou seja, aquele da câmara frontal à altura dos olhos do fotógrafo (como em Tucano de bico preto ou Tocador de rabeca), comprometido com a representação mais que convencional (MACHADO, 1984) - esquivando-se da desmistificação da autoridade do olho-sujeito burguês de privilegiar um determinado ponto de vista e estabelecer por si só uma hierarquia de valores. Este olho sujeito presente nas fotografias de Alcântara impõe-se ao espectador dando-lhe a impressão que suas imagens são sempre "naturais", "realistas", e portanto "imparciais": é como se elas tivessem sido produzidas a despeito da ação humana BARRETT, 2000) e sem nenhum interesse ideológico, mostrando que de fato o mundo "é" da forma como se apresenta na imagem.

Estas representações "fiéis" e "completas" da realidade não se restringem somente ao campo das produções ditas artísticas. Tomemos as imagens fotojornalísticas como exemplo. O fotojornalismo, ao contrário do que se pretende e de como se apresenta, não é de fato uma representação realista e objetiva da realidade. Todas as escolhas feitas pelo fotógrafo, incluindo o equipamento (analógicos ou digitais, formatos, lentes, filtros, etc.) o enquadramento (composição da imagem utilizando-se diferentes retas, curvas, planos, ou regras de "boa composição": a regra 
dos terços ${ }^{6}$ ou aquela dos pontos de ouro ${ }^{7}$, sem mencionar a decisão do que incluir ou não e de como - se é que será capaz - o fotógrafo fará ilusão ao assunto ou tema extra quadro), e o ponto de vista adotado (visão "realista" ou "distorcida" da "realidade"). Outras escolhas também influenciarão a representação da imagem, como: a escolha de diafragmas que permitirão maior ou menor profundidade de campo, velocidades que atribuirão maior ou menor movimento à imagem, a escolha de filmes mais ou menos sensíveis à luz, diferentes formas de revelação deste filme, diferentes maneiras de ampliação da imagem, valores tonais a serem atribuídos, possíveis alterações ou manipulações - analógicas ou digitais - para "correção" da imagem, etc. Tudo isto revela que a produção da imagem foto-jornalística não é senão também uma tomada de posição, e não uma representação "realista" e objetiva da realidade do mundo como ele "é".

A imagem pós-moderna, além de imersa naquela "pop-history" e ter um caráter fragmentário e esquizofrênico, é também brilhante. Seu caráter brilhante auxilia o embelezamento da forma utilizada com o intuito de facilitar cada vez mais o consumo de mercadorias (e da própria arte como mercadoria): esta forma, cada vez mais embelezada (e cada vez mais dissociada do conteúdo da obra), torna-se mais facilmente consumível. Portanto, a principal função deste caráter brilhante na imagem pós-moderna é a de adornar a forma para que esta se torne mais e mais "palatável", "visualmente aprazível", e portanto consumível. Este embelezamento da forma, através do caráter brilhante que a imagem pós-moderna adquiriu e do qual se serve para facilitar o fluxo da arte como mercadoria, não é outro mero procedimento de natureza puramente estilística. Ao contrário, é mais um recurso a ser utilizado em uma batalha ideológica travada no campo do olhar. Retomando a prática de mapeamento cognitivo, Jameson historiciza inclusive os modos de percepção humana. Segundo ele, o aparelho sensorial humano foi colonizado pelo capital e fragmentou-se de acordo com a lógica do capitalismo (JAMESON, 1991). Assim, as capacidades humanas de quantificar são privilegiadas enquanto que o locus do "desejo" se restringe ao "olhar" (numa relação que a psicanálise procurou explicar). Desta forma, há uma compensação utópica do desejo triunfando sobre as quantidades, fazendo com que o ver ganhe novas proporções, exageradamente enfáticas. Desta maneira, o olhar transforma-se no campo de batalha ideológica e o visual é dominado por formas de domesticação: controla-se o que ver, ensina-se o que e como ver, e "onde colocar o desejo". A indústria cinematográfica de Hollywood é o exemplo clássico desta forma de dominação do olhar. A obra de arte pós-moderna, não somente através do cinema, mas em maneiras diversas da representação artística como pintura ou fotografia, estimula tanto a domesticação do olhar bem como a colocação do desejo na mercadoria a ser consumida (processo este que atinge seu auge na fotografia publicitária). ${ }^{8}$

\footnotetext{
${ }^{6}$ Regra que prescreve a divisão da imagem em partes iguais.

${ }^{7}$ Regra que sugere a disposição dos diferentes sujeitos na intersecção das linhas que dividem a imagem em partes de igual tamanho ou proporção.

${ }^{8}$ Este processo se inicia no surgimento da pintura a óleo e se consolida a partir do século XVI com o estabelecimento de normas próprias deste tipo de pintura, que pretende, justamente por causa da ascensão da burguesia e de sua necessidade de expressar uma visão de mundo que com a utilização de técnicas anteriores como a têmpera ou o afresco seria impossível, ratificar que a partir de então a mercadoria e o capital passam a ocupar papel central - até se imporem por completo na pós-modernidade.
} 
A valorização excessiva da forma, seja através da utilização de recursos tecnológicos ou do caráter brilhante da imagem acima descrito, nos leva à outra característica das imagens pós-modernas: o que Jameson denominou de desaparecimento do afeto (JAMESON, 1991). O afeto ao qual se refere são os significados e os contextos humanos em torno do conteúdo da obra (BENJAMIN, 1993). Uma vez que a relação forma-conteúdo é inexistente, como anteriormente mencionado, desaparece o afeto. O que "vale" então é somente a forma pela forma, inserida em um processo artístico que se limita a canibalizar estilos anteriores. Não se trata aqui de uma canibalização paródica nos termos modernistas ${ }^{9}$, uma vez que não se estabelecem quaisquer relações entre os estilos anteriores e a produção pósmoderna. Ao contrário, trata-se de uma "canibalização aleatória" de estilos passados, de um pastiche, outro dominante cultural pós-moderno (JAMESON, 1991): um esvaziamento - historicamente determinado - da forma artística e das relações entre estilos anteriores e a atual produção artística pós-moderna. $O$ pastiche, este dominante cultural pós-moderno por excelência, seria assim uma purgação dos conteúdos político-históricos, um "jogo formal", uma arte que "mira seu próprio umbigo", em cópias de diversos estilos anteriores totalmente desconexos de seus referentes sócio-históricos. O pastiche pós-moderno seria assim o Belo, a arte em si e para si, desprovido do Sublime modernista, uma experiência trans-estética que transcende o Belo e tenta estabelecer relações entre a arte e a sociedade ${ }^{10}$.

\section{A crítica à imagem na pós-modernidade}

Sem perder de vista a questão inicialmente posta por Jameson e sua proposta historicista de abordá-la, constatamos que a produção imagética pós-moderna, através de simulacros ocos cujo único conteúdo é somente sua forma, é possivelmente a principal característica de uma sociedade que reflete em sua produção artística uma inversão de valores sem precedentes: o valor de troca dos objetos, ideias e conceitos foi tão amplamente generalizado ao ponto de obscurecer a memória de seu valor de uso. Segundo Guy Debord, este tipo de imagem tornou-se "a forma final da reificação da mercadoria" (DEBORD, 1997). Este caráter da imagem pós-moderna nos remete novamente à questão do possível poder cognitivo destas imagens de relevar algo de "verdade" sobre seu tempo através de códigos que expressam tão evidentes "mentiras". Parece de fato cada vez mais difícil que estas imagens-simulacro figurem representações de nossa realidade cotidiana, uma vez que tais imagens primam cada vez mais pelo apego ao ponto de vista do individual, do fragmento com sua "vida própria", e que este seja representado através da utilização desses códigos que, como anteriormente mencionado, estão a serviço da lógica da mercadoria. Então como figurar estes "momentos de verdade" nesta lógica, na qual o passado como referente é gradualmente excluído, deixando-nos apenas com "textos" imersos naquele "nada" "ahistórico" que permeia a obra pós-moderna?

\footnotetext{
9 Alguns exemplos de paródias modernistas incluem "Ulisses", de James Joyce e suas relações com a obra de Homero e, na pintura, "As Meninas" de Picasso, que estabelece relações com "As Meninas" de Velásquez.

10 Reflexões sobre o Belo e o Sublime encontram-se na filosofia clássica alemã em obras como Crítica do Juízo, de Kant e Estética, de Hegel.
} 
Jameson parece oferecer uma resposta complexa, porém exequível: a utilização do mapeamento cognitivo como instrumento de análise crítica. A apreciação crítica deste procedimento leva em consideração o fato de que não existe um ponto de vista fora da ideologia. Portanto, a chamada "crítica objetiva", imparcial e desinteressada seria um embuste, já que toda ação crítica é também uma ação ideológica, que serve interesses precisos (naturalmente os diferentes interesses em jogo variam enormemente; cabe ao crítico escolher com consciência sua abordagem) Assim, segundo Jameson, a ação política da crítica materialista se daria, dentro do panorama aqui descrito, através do mapeamento cognitivo da organização e avaliação do mundo do ponto de vista de dentro da ideologia. A abordagem crítica seria, assim, uma relação entre história e forma artística, ou seja, entre o "como" os contextos externos à obra encontram-se presentes na fatura formal desta obra. Não me refiro aqui a uma relação unívoca e mecânica, entre uma história pré-conhecida e conteúdos explícitos na obra de arte (por exemplo, intuir que uma vez que o século XVIII viveu um período de grande ascensão da burguesia, havia nas artes em geral uma especial predileção pelo retrato como gênero artístico. Ou, no campo da fotografia, argumentar que a produção de fotografias de cidade feitas por Eugène Atget, bem como a forma que o fotógrafo utilizava, derivavam única e exclusivamente do fato de que no final do século XIX e início do século XX houve um enorme crescimento dos núcleos urbanos na Europa), mas a uma descrição da forma enquanto estrutura e, ao mesmo tempo, dos conteúdos sócio-históricos que nela encontram-se decantados. A desafiadora tarefa crítica reside na análise dos conteúdos "externos" e com papel estrutural na obra de arte.

\section{Bibliografia}

ADORNO, T. \& HORKHEIMER, M. Dialect of enlightenment. London; New York: Verso, 1995.

ALCANTARA, A. Terra Brasil. São Paulo: DBA - Dórea Books and Art, 1998.

BENJAMIN, W. Obras escolhidas: magia e técnica, arte e política. São Paulo: Brasiliense, 1993.

BERGER, J. Ways of seeing. Londres: British Broadcasting Corporation \& Penguin Books, 1977.

BERRETT, T. Criticizing photographs: an Introduction to Understanding Images. Mountain View, California, London \& Toronto: Mayfield Publishing Company, 2000.

CEVASCO, M. E. Diversidade cultural e globalização. Revista da Biblioteca Mário de

Andrade: Literatura e Diversidade Cultural. São Paulo: v. 59, jan./dez. 2001.

DEBORD, G. A sociedade do espetáculo. Rio de Janeiro: Contraponto, 1997.

EAGLETON, T. The significance of theory. Oxford: Blackwell, 1990.

FEATHERSTONE, M. Cultura de consumo e pós-modernismo. São Paulo: Studio Nobel, 1995.

FREUD, S. The essentials of psycho-analysis. Londres: Penguin, 1986. 
HARDT, M. \& WEEKS, K. The Jameson reader. Londres: Blackwell Publishers, 2000. HEGEL, G.W.F. Estética. Lisboa: Guimarães Editores, 1993.

JAMESON, F. Postmodernism, or the cultural logic of late capitalism. London \& New York: Verso, 1991.

"Reificação e utopia de massa". In Jameson, F. As marcas do visível. Rio de Janeiro: Graal, 1995.

A cultura do dinheiro. Petrópolis: Vozes, 2001.

LAVRENTIEV, A. Alexander Rodchenko: Photography 1924-1954. Köln: Könemann, 1995.

MACHADO, A. A ilusão especular: introdução à fotografia. São Paulo: Brasiliense, 1984.

MAILLET, L. B. Atget Paris. Paris: Hazan, 1992.

MARCUSE, H. Cultura e sociedade. São Paulo: Paz e Terra, 1997.

MARTINELLI, P. Amazônia, o povo das águas. São Paulo: Terra Virgem Editora, 2000.

MARX, K. The Eighteenth Brumaire of Louis Bonaparte. In MARX, K. Selected writings. SIMON, Lawrence $H$. (ed.) Indianápolis; Cambridge: Hackett Publishing Company, 1994.

MULHERN, F. Culture/metaculture. London; New York: Routledge; Taylor \& Francis group, 2000.

SALLENAVE, D. André Kertész. Paris: Centre National de la Photographie, 1985.

STEIN, S. A. Van Gogh: a Retrospective. China: Beaux Arts Editions, 1986.

TRIP. v. 14, n. 86, fevereiro de 2001.

XAVIER, I. Cinema: revelação e engano. In NOVAES, A. (org). O olhar. São Paulo: Companhia das Letras, 1989.

Title: Painting, photography, and art criticism in post-modernity

Abstract: This article intends to present and discuss some of the most typical characteristics of images produced in what is conventionally described as "postmodernism", attempting to establish some relations between the material constraints for their production, the historic basis on which they find themselves and the evaluation made by an influential part of the critic.

Keywords: Painting. Photography. Art criticism. Post-modernism.

Recebido em: 03/04/2013. Aceito em 17/06/2013. 